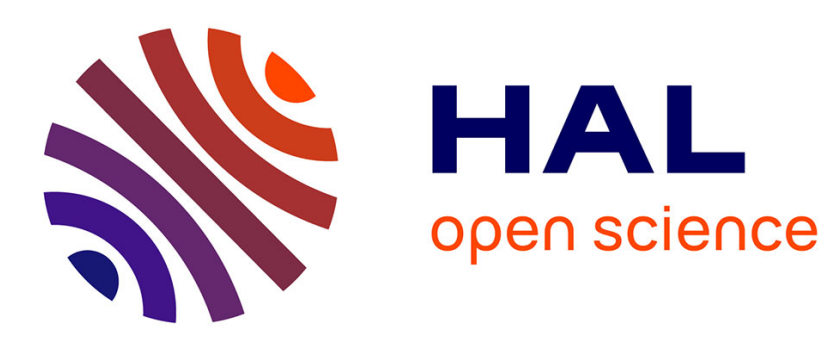

\title{
Photoacoustic study of the effect of fuel oil on the photosynthetic system of algae Scenedesmus armatus
}

J. Szurkowski, Z. Tukaj

\section{To cite this version:}

J. Szurkowski, Z. Tukaj. Photoacoustic study of the effect of fuel oil on the photosynthetic system of algae Scenedesmus armatus. Journal de Physique IV Proceedings, 1994, 04 (C7), pp.C7-535-C7-538. 10.1051/jp4:19947126 . jpa-00253180

\section{HAL Id: jpa-00253180 https://hal.science/jpa-00253180}

Submitted on 1 Jan 1994

HAL is a multi-disciplinary open access archive for the deposit and dissemination of scientific research documents, whether they are published or not. The documents may come from teaching and research institutions in France or abroad, or from public or private research centers.
L'archive ouverte pluridisciplinaire HAL, est destinée au dépôt et à la diffusion de documents scientifiques de niveau recherche, publiés ou non, émanant des établissements d'enseignement et de recherche français ou étrangers, des laboratoires publics ou privés. 


\title{
Photoacoustic study of the effect of fuel oil on the photosynthetic system of algae Scenedesmus armatus
}

\author{
J. Szurkowski and Z. Tukaj* \\ Institute of Experimental Physics, University of Gdansk, Wita Stwosza 57, 80-952 Gdansk, Poland \\ * Department of Plant Physiology, University of Gdansk, Marszalka Pilsudskiego 46, 81-378 Gdynia, \\ Poland
}

\begin{abstract}
Photoacoustic (PA) spectroscopy was applied to study variability in the photosynthetic energy storage (ES) and changes in the PA-signal amplitude of the green alga Scenedesmus armatus, grown in a batch culture in the presence of aqueous fuel-oil extract (AFOE). The adaptation process of the alga was observed for 16 days by means of intercomparison between the PA-signal of the alga cultures in the polluted environment and a control culture. Characteristic changes in the ultrastructure of the alga have been observed.
\end{abstract}

\section{INTRODUCTION}

Photoacoustic (PA) technique has been successfully employed to study the photosynthetic systems with a variety of useful results including direct measurements of photosynthetic energy storage (ES) [1] and $\mathrm{O}_{2}$ evolution in intact leaves $[2,3]$.

When the sample placed in a closed-type PA cell is exposed to a modulated light, part of the absorbed light energy is emitted in a form of modulated heat (photothermal signal) as a result of thermal deactivation of pigments. An additional fraction of the energy used for photochemical processes which lead to emission of $\mathrm{O}_{2}$ (modulated emission of $\mathrm{O}_{2}$ ), and appears as a photobaric signal. Both heat and oxygen emission induce pressure changes in the photoacoustic cell that are measured by a microphone. By measuring heat emission in the presence or absence of a nonmodulated saturating light background (at a modulation frequency high enough for the photobaric component of the signal to be neglected) the photosynthetic ES is evaluated.

In this paper the emphasis was placed on inhibitory effects of aqueous fuel oil extract (AFOE) on the photosynthesis and its influence on the morphological changes in the green microalga Scenedesmus armatus.

\section{MATERIALS AND METHODS}

The green microalga Scenedesmus armatus, isolated from the Gulf of Gdansk, Baltic Sea (obtained from Institute of Oceanology, Polish Academy of Sciences at Sopot) was used in this study. Detailed informations on alga cultures and characterisation of growth measurements can be found elsewhere [4].

Diesel No. 2 fuel oil (Polish Standard: PN - 67/C - 96048) obtained from Gdansk Refinery was used in this work. The aqueous fuel oil extract (AFOE) was prepared by mixing a volume of $50 \mathrm{~cm}^{3}$ of oil with $1 \mathrm{dm}^{3}$ of a sterilised liquid Bold Basal Medium (BBM) in a bottle tightly sealed with a teflon-plug. The mixture was agitated for $24 \mathrm{~h}$ by means of a magnetic stirrer and then transferred to a separating funnel for about $2 \mathrm{~h}$ before algae was tested or the aqueous layer sampled for hydrocarbon analysis. The lower 
aqueous phase was carefully siphoned from below the surface of the oil slick. This extract was diluted with a BBM medium to $90 \%, 50 \%$ and $10 \%$ concentrations (v/v), which were used immediately in the experiments.

A $100-500 \mathrm{~cm}^{3}$ undiluted aliquot was taken for analysis. Total amount of fuel-oil hydrocarbons in water samples (carbon tetrachloride extractable oil) were determined by an infrared spectrophotometry method [5]. The concentration of hydrocarbons in AFOE measured by the above method is $49.8 \pm 9.1$ $\operatorname{ppm}(\mathrm{n}=5)$. Qualitative characterisation of AFOE can be found elsewhere [4].

Photoacoustic measurements were made with a lab-built PA spectrometer similar to that described in detail elsewhere [6]. Percentage ES was calculated as $(a-b) / a * 100$ (and expressed in per cent), where $a$ is the PA signal produced by the modulated light (while simultaneously nonmodulated background light of $2000 \mu \mathrm{Em}^{-2} \mathrm{~s}^{-1}$ was added) and $b$ is the PA signal observed in the modulated light alone. Addition of strong background light saturates photochemistry in the sample, increasing the absorbed modulated light to heat conversion to nearly $100 \%$ and producing a maximal PA signal proportional to absorption of the modulated light by the sample. In the presence of the modulated light alone, photochemistry is not saturated and a reduced PA signal is observed as a result of storage of a substantial part of the absorbed light as product(s) of photosynthesis.

Energy storage measurements were carried out at different concentrations 24 hours after adding AFOE to the culture. This time delay is comparable to interval of generation change for algae Scenedesmus armatus. The adaptation process of algae to a new environment contaminated by a fuel oil product was observed for 16 days by means of intercomparison between the PA spectra of algae's cultures in the polluted environments and these of control culture. Energy storage measurements were performed with monochromatic light of $680 \mathrm{~nm}$ modulated at $80 \mathrm{~Hz}$, at which $\mathrm{O}_{2}$ component is very low and its effect on determination of ES is negligible.

Observations of morphological changes were performed using a JEM 7A microscope (Jeol).

\section{RESULTS AND DISCUSSION}

The effect of AFOE on photosynthetic ES of alga's culture after a 24-hour growth is depicted in Fig.1. Since this period is comparable to a generation's time for Scenedesmus armatus algae, the obtained results reflect for the most part adaptive changes exhibited by algae during a single generation cycle. For all AFOE concentrations applied, measured ES values for affected samples were lower than those for control samples. The differences increase with increasing AFOE concentration in the culture. We were concerned with inhibition of photosynthesis the intensity of which depends on concentration of diesel extracts [7]. A relative decrease (38\%) of photosynthetic ES for a $90 \%$ extract of AFOE (relative to a control sample) is registered. Results obtained suggest a linear character of ES dependence.

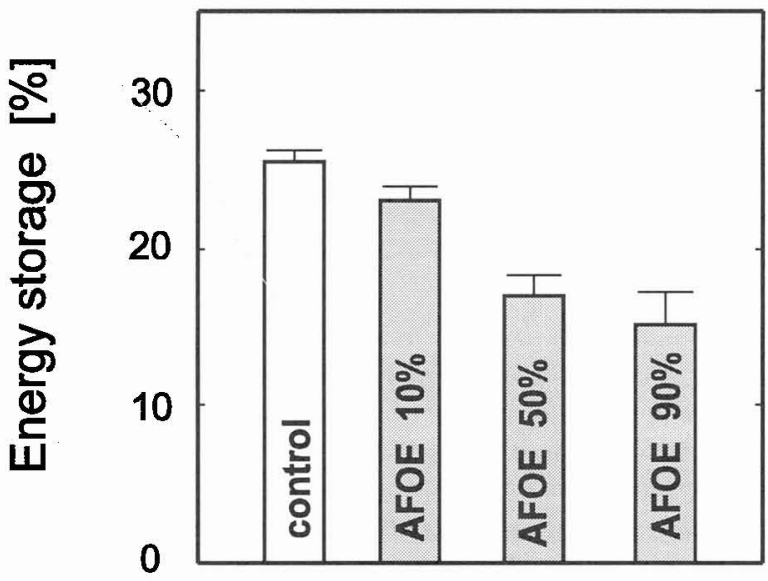

Fig.1 Energy storage (ES) versus concentration of AFOE for Scenedesmus armatus after $24 \mathrm{~h}$. 
Tab.1 Time dependence of the ratio of PA intensity for samples with fuel oil ( $90 \%$ AFOE) to that of control samples at several excitation wavelengths.

\begin{tabular}{|c|c|c|c|}
\hline Day & \multicolumn{3}{|c|}{ Wavelength of excitation [nm] } \\
\hline & $\mathbf{4 3 5}$ & $\mathbf{4 8 4}$ & $\mathbf{6 8 4}$ \\
\hline \hline 1 & 1.13 & 1.15 & 1.38 \\
\hline 3 & 1.30 & 1.41 & 1.53 \\
\hline 7 & 1.78 & 2.06 & 1.94 \\
\hline 9 & 1.38 & 1.54 & 1.61 \\
\hline 12 & 1.28 & 1.41 & 1.69 \\
\hline 16 & 1.24 & 1.31 & 1.32 \\
\hline
\end{tabular}

Data concerning the effect of AFOE (at 90\%) on changes in the ratios of PA-signal intensity (at 684, 484 and $434 \mathrm{~nm}$ ) observed for samples with fuel oil to that of control samples are collected in Table 1. For long-term cultures signal depends both on condition of the photosynthetic apparatus and alga's morphology. Two of these maxima (at 684 and $435 \mathrm{~nm}$ ) are within absorption bands of chlorophyll. The maximum at $484 \mathrm{~nm}$ originates from the presence of carotenoids (supporting pigments in a photosynthetic process) in the sample. Changes of signal ratios reach maxima at wavelengths corresponding to the maximum of chlorophyll absorption in the spectrum red band, which is particularly sensitive to a change of energy transfer to the reaction centres. It also appears at the maximum related to the carotenoids absorption, that exhibit an increase of PA-signals with decreasing yield of energy transfer to chlorophyll. The ratio of PA signal for samples with fuel oil to a reference one for control samples reaches its maximum after 7 days of culture growth. It is known that at such period corresponds to maximal changes in chloroplasts structure under the action of AFOE [8].
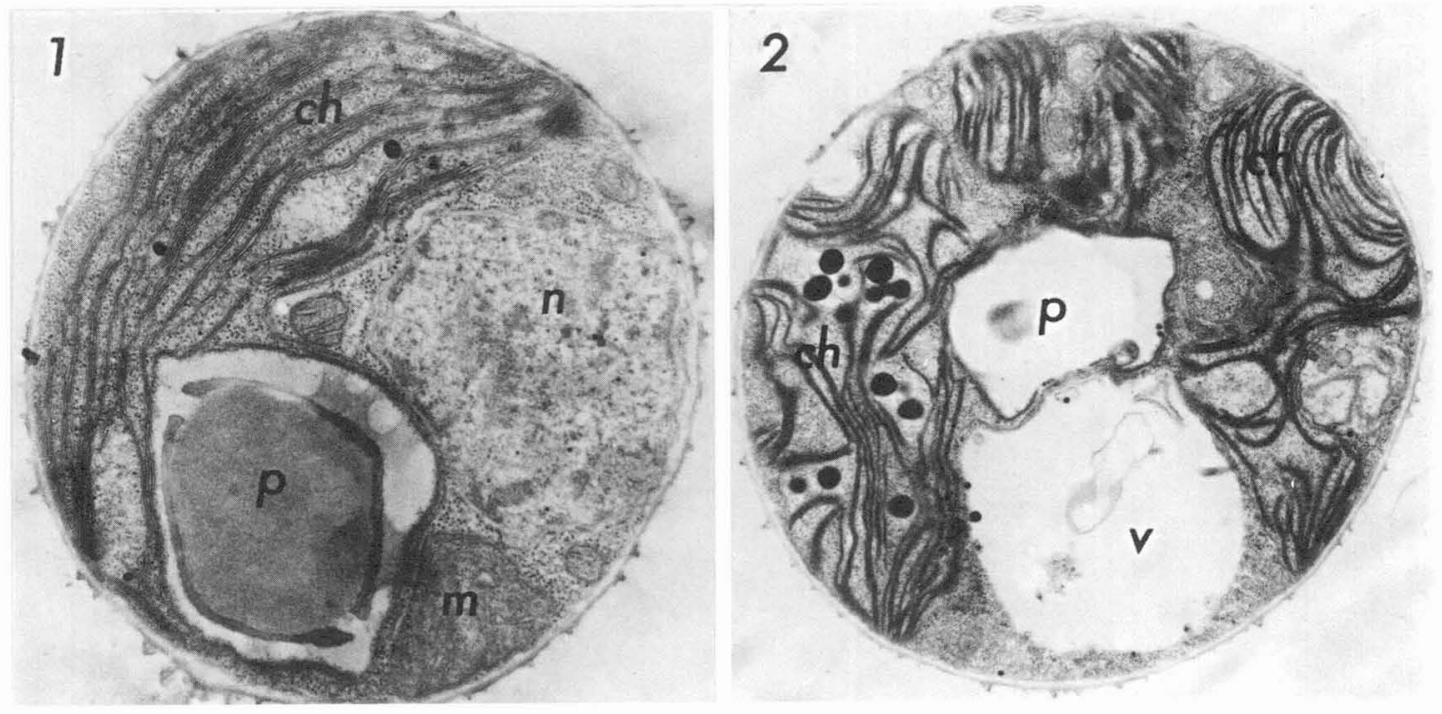

Fig.2 Cross-section of Scenedesmus armatus cells cultured without (Fig. 2.1) and with AFOE (Fig.2.2) for 7 days; ch-chloroplast, m-mitochondrium, n-nucleus, p-pyrenoid, v-vacuole. Magn. Fig. 2.1 - 28,000 and Fig. 2.2 - 17,700. 
The fine structure of Scenedesmus armatus cells cultured for 7 days without and with AFOE (90\%) is displayed at Fig. 2.1 and Fig. 2.2 respectively. In the control cell, elongated and stacked thylacoids of chloroplast are arranged almost parallel to one another. In some places neighbouring stacks adhere to each other to form clusters, resembling the grana of higher plants. On the contrary, distortion of thylacoids can be seen in a cell treated with AFOE. The whole chloroplast becomes strongly folded, parts of which are visible almost throughout the cell. The number and the size of plastoglobules are greater in such chloroplast (black circles).

Photoacoustic spectroscopy appears simple and in combination with other methods, very promising method to study the contamination effects on biological environmental systems.

\section{ACKNOWLEDGEMENT}

This work was supported by the Polish Council for Scientific Research (KBN) under Grant No. PB 2273/2/91/92.

\section{REFERENCES}

[1] Cha Y. and Mauzerall D.C., Plant Physiol. 100 (1992) 1869-1877.

[2] Mauzerall D.C., Plant Physiol. 94 (1990) 278-283.

[3] Poulet P., Cahen D. and Malkin S., Biochim. Biophys. Acta 724 (1983) 433-446.

[4] Tukaj Z., Environ. Pollut. 47 (1987) 9-24.

[5] Gruenfeld M., ASTM STP 573 (1975) 290-308.

[6] Carpentier R., LaRue B. and Leblanc R.M., Arch. Biochem. Biophys. 222 (1983) 403-410.

[7] Liebe B. and Fock H.P., J. Gen. Microbiol. 138 (1992) 973-978.

[8]Tukaj Z., Protoplasma 151 (1989) 47-56. 